\title{
(2) OPEN ACCESS \\ Short-term efficacy of latanoprostene bunod for the treatment of open-angle glaucoma and ocular hypertension: a systematic literature review and a network meta-analysis
}

\author{
Paul Harasymowycz, ${ }^{1}$ Catherine Royer, ${ }^{2}$ Amy Xianying Cui, ${ }^{3}$ Martin Barbeau, ${ }^{3}$ \\ Katherine Jobin-Gervais, ${ }^{3}$ Karine Mathurin, ${ }^{2,4}$ Jean Lachaine (D) , 2,4 \\ Catherine Beauchemin ${ }^{2,4}$
}

- Additional material is published online only. To view, please visit the journal online (http://dx.doi.org/10.1136/ bjophthalmol-2020-317262).

${ }^{1}$ Ophthalmology, University of Montreal, Montreal, Québec, Canada

${ }^{2}$ Pharmacoeconomics and Outcomes Research, PeriPharm Inc, Montreal, Québec, Canada ${ }^{3}$ Market Access, Bausch Health Canada Inc, Laval, Quebec, Canada

${ }^{4}$ Pharmacy, Université de Montréal, Montreal, Quebec, Canada

\section{Correspondence to} Professor Jean Lachaine, Pharmacy, Université de Montréal, Montreal, H3T 1J4, Canada:

jean.lachaine@umontreal.ca

Received 18 June 2020 Revised 4 November 2020 Accepted 4 December 2020
Check for updates

(c) Author(s) (or their employer(s)) 2021. Re-use permitted under CC BY-NC. No commercial re-use. See rights and permissions. Published by BMJ.

\section{To cite: Harasymowycz $\mathrm{P}$} Royer C, Cui AX, et al. Br J Ophthalmol Epub ahead of print: [please include Day Month Year]. doi:10.1136/ bjophthalmol-2020-317262

\begin{abstract}
Background/aims To assess the comparative efficacy of latanoprostene bunod (LBN), a novel prostaglandin analogue (PGA), to other medications for openangle glaucoma and ocular hypertension on lowering intraocular pressure (IOP).
\end{abstract}

Methods A systematic literature review adapted from the Li et al (Ophthalmology, 2016) study was conducted. Medline, Embase and PubMed were searched for randomised controlled trials published between 1 January 2014 and 19 March 2020. Studies had to report IOP reduction after 3 months for at least two different treatments among placebo, PGAs (bimatoprost $0.01 \%$, bimatoprost $0.03 \%$, latanoprost, LBN, tafluprost, unoprostone) or apraclonidine, betaxolol, brimonidine, brinzolamide, carteolol, dorzolamide, levobunolol, timolol, travoprost. A Bayesian network meta-analysis was performed to provide the relative effect in terms of mean difference (95\% credible interval) of IOP reduction and ranking probabilities. Surface under the cumulative ranking curve (SUCRA) was generated.

Results A total of 106 trials were included with data for 18523 participants. LBN was significantly more effective than unoprostone $(-3.45(-4.77$ to -2.12$))$. Although relative effect was not significative, compared with other PGAs, LBN numerically outperformed latanoprost $(-0.70(-1.83$ to 0.43$))$ and tafluoprost $(-0.41(-1.87$ to 1.07$))$, was similar to bimatoprost $0.01 \%(-0.02(-1.59$ to 1.55$))$ and was slightly disadvantaged by bimatoprost $0.03 \%(-0.17(-1.42$ to 1.07$)$ ). LBN was significantly more efficient than the beta-blockers apraclonidine, betaxolol, brimonidine, brinzolamide, carteolol, dorzolamide and timolol. According to SUCRA, LBN was ranked second after bimatoprost $0.03 \%$, followed by bimatoprost $0.01 \%$.

Conclusion LBN was significantly more effective than the PGA unoprostone and most of the beta-blockers. Compared with the most widely used PGAs, LBN numerically outperformed latanoprost and travoprost and was similar to bimatoprost $0.01 \%$.

\section{INTRODUCTION}

Glaucoma is a group of progressive optic neuropathies characterised by degeneration of retinal ganglion cells which may lead to vision loss and blindness. ${ }^{1}$ It is the number one cause of irreversible vision loss and the second leading cause of blindness worldwide. ${ }^{2}{ }^{3}$ Primary open-angle glaucoma (POAG) is the most common form of the disease in North America with a prevalence of 3.3\% (2.7 million people) in adults aged between 40 and 80 years in $2013 .^{4}$

The goal of treatment is to reduce intraocular pressure (IOP), which is the only modifiable risk factor at this time. ${ }^{3}$ Initial treatment consists of topical therapies with several classes available, including prostaglandin analogues (PGAs), $\alpha$-adrenergic agonist, beta-blockers and carbonic anhydrase inhibitors and parasympathomimetic agents. ${ }^{367}$ Among these, PGAs are the most effective medication because of their unmatched safety profile, IOP-lowering capabilities and their oncedaily administration, with latanoprost, bimatoprost and travoprost being the most frequently used. ${ }^{8}$ Of note, in 2012, Lumigan (bimatoprost 0.03\%) was discontinued and replaced by Lumigan RC (bimatoprost $0.01 \%$ ) due to its favourable tolerability profile. ${ }^{9}$

In order to compare the different treatments a comprehensive assessment of their relative efficacy is crucial for clinicians and healthcare decisionmakers, ${ }^{8} 10$ however, no head-to-head trials comparing all relevant competing therapies have been published. In the absence of direct evidence, the use of a network meta-analysis (NMA) may provide useful evidence. ${ }^{10}$ In 2016, Li et al published the results of a systematic review and an NMA which aimed to compare the effectiveness of firstline medications for patients with POAG or ocular hypertension $(\mathrm{OH})$ and to provide relative ranking of these treatments. The authors conducted a systematic review in March 2014 in order to identify all randomised controlled trials (RCTs) comparing single active topical medication with no treatment/ placebo or with another single topical treatment. Following a systematic review of 114 eligible trials, results of the NMA indicated that, compared with beta-blockers, $\alpha$-adrenergic agonists and carbonic anhydrase inhibitors, PGAs were more efficacious in reducing IOP at 3 months. Authors also concluded that drugs within the PGA class, namely bimatoprost, latanoprost and travoprost were among the most efficacious, with intraclass difference found to be small and not clinically meaningful. ${ }^{11}$ 
Vyzulta (latanoprostene bunod (LBN) ophthalmic solution, $0.024 \% \mathrm{w} / \mathrm{v}$ ), a novel nitric oxidedonating prostaglandin F2 $\alpha$ analogue has received approbation for commercialisation in six different countries. ${ }^{12}$ The safety and efficacy of LBN has been well established through clinical studies (APOLLO and LUNAR studies), ${ }^{13}{ }^{14}$ where LBN demonstrated enhanced efficacy compared with latanoprost and timolol. ${ }^{13-15}$ However, the effectiveness of LBN in comparison to other topical therapies other than latanoprost and timolol has not yet been evaluated. The objective of this study was to assess, through a systematic review and an NMA, the relative efficacy, as well as provide a relative ranking, of LBN compared with other topical medications, with a focus on PGAs, for the treatment of POAG and OH.

\section{MATERIAL AND METHODS}

The pool of studies included in Li et al ${ }^{11}$ previously described was considered and an exhaustive literature review was performed for studies published after 2013. An NMA was conducted according to a predefined protocol and was conformed to the Preferred Reporting Items for Systematic Reviews and Meta-Analyses ${ }^{16}$ extension for NMA. The review question was established using the population, intervention, comparators, outcomes (PICO) framework. This systematic review was adapted from the work by Li et al previously described. ${ }^{11}$

\section{Search strategy}

MEDLINE, EMBASE and PubMed databases were searched on 19 March 2020 to identify RCTs published in English or French between 1 January 2014 and 19 March 2020. A manual search of reference lists was also performed to identify potentially relevant papers and systematic reviews. The same search strategy elaborated by Li et al was used but 'latanoprostene bunod' was added as a keyword. ${ }^{11}$ Detailed search strategies are presented in online supplemental appendix A.

\section{Eligibility}

Studies were selected if they reported relative efficacy between at least two different treatments (placebo, bimatoprost $0.01 \%$, bimatoprost $0.03 \%$, latanoprost, LBN, tafluprost, unoprostone, apraclonidine, betaxolol, brimonidine, brinzolamide, carteolol, dorzolamide, levobunolol, timolol or travoprost) in terms of IOP reduction after 3 months of usage. All eligibility criteria were defined a priori and were rigorously considered assuming the similarity assumption. Inclusion criteria included the following: RCTs with a parallel-group design (cross-over trials excluded); at least $60 \%$ of patients with a diagnostic of POAG and/or $\mathrm{OH}$; trials that assess a monotherapy regimen (combination of medical treatments excluded); studies published in English and French between 1 January 2014 and 19 March 2020.Trials were excluded if they enrolled fewer than 10 participants in each group or if they evaluated a combination of medical treatments. Although no maximum or minimum duration of treatment was required, participants had to be followed for at least 28 days after randomisation.

\section{Study selection and data extraction}

Two reviewers independently screened the titles and abstracts of publications for potential eligibility. Using a predefined eligibility form (online supplemental appendix B), both reviewers screened the full text of all potentially eligible trials. Any disagreements were resolved by consensus or with the help of a third reviewer.

Data extraction was performed by two independent reviewers. Data extracted included: first author's name, year of publication, trial design, location of trial, sample size, patients' baseline characteristics, intervention characteristics and quantitative results with regard to treatment effect. For studies presenting multiple treatment durations, the duration closest to 3 months was used. If many IOP measures were available, the selection was made in this order: mean diurnal IOP, 24-hour mean IOP, peak IOP reduction and morning IOP. Any discrepancies were resolved by consensus or with the help of a third reviewer.

\section{Quality assessment}

As part of their systematic review, Li et al assessed the quality of included trials using the Cochrane Risk of Bias Tool, where the following seven methodological domains were graded as 'low', 'high' or 'unclear' risk of bias: sequence generation, allocation concealment, blinding of participants and personnel, blinding of outcome assessors, funding of the trial and financial relationship reported by the authors. ${ }^{11} 17$ Based on their work, new trials identified by the current systematic review were assessed using the same method.

\section{Outcome definition}

The primary outcome was defined as the mean reduction (MR) of IOP in continuous mmHg units after 3 months of treatment. The mean difference (MD) of the MR of IOP between two treatments with a $95 \%$ CI or credible interval (CrI) was calculated. An MD under 0 indicated that the treatment of reference performed a higher IOP reduction relative to its comparator and was therefore more effective.

\section{Data synthesis and analysis}

Using the 'meta' package in $\mathrm{R}$, a pairwise meta-analysis (ie, direct comparisons) with a random-effect model was conducted for every treatment comparison with at least two trials. Statistical heterogeneity between studies was assessed using the $\mathrm{I}^{2}$ statistic, which describes the percentage of variability in effect estimates that is due to heterogeneity rather than sampling error (chance). ${ }^{18}$ Cochrane Handbook developed a rough guide for interpretation of $\mathrm{I}^{2}$ : less than $40 \%$ might not be important, 30\%-60\% may represent moderate heterogeneity; 50\%-90\% may represent substantial heterogeneity and 75\%-100\% represented considerable heterogeneity. ${ }^{18}$ Pairwise comparisons with an $\mathrm{I}^{2}$ value greater than $65 \%$ were investigated to identify studies possibly causing heterogeneity.

An NMA, which combined direct and indirect comparisons, was conducted using a Bayesian random-effect model with Markov Chain Monte Carlo simulations executed with the 'gemtc' package in R. ${ }^{19}$ Using four parallel chains, 50000 samples after 20 000-sample burn-in were obtained in each chain. Convergence of the model was assessed using the BrooksGelman-Rubin diagnostic in the 'coda' package in R. Consistency of the NMA, defined as a statistical discrepancy between direct and indirect comparison results, was evaluated using a node-splitting approach with the 'gemtc' package in R. ${ }^{19}$

The model ranked each treatment by their relative effect (probabilities of being more effective). Cumulative probability of being the most effective treatment was calculated. With that, the surface under the cumulative ranking curve (SUCRA) of each treatment is obtained. ${ }^{20}$ Specifically, SUCRA is a numeric presentation of the overall ranking and presents a single number, ranging from $0 \%$ to $100 \%$, associated with each treatment, where $0 \%$ represents the least effective treatment and $100 \%$ represents the most effective treatment. ${ }^{21}$ 


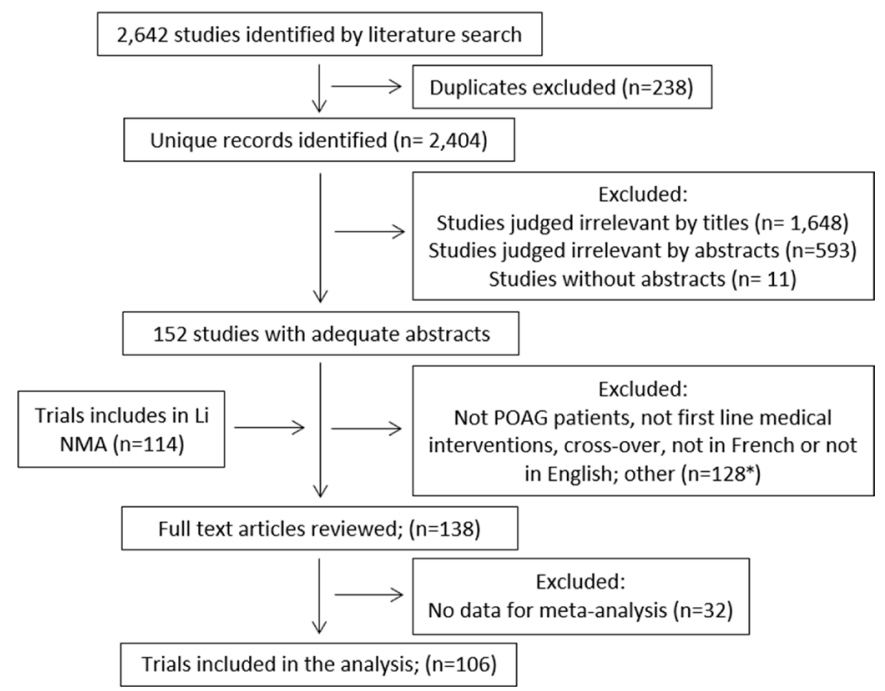

Figure 1 Organisational chart of the literature review. *Among the 128 excluded studies, seven were included in the Li et al publication. NMA, network meta-analysis; POAG, primary open-angle glaucoma.

Sensitivity analyses were conducted to assess the impact of heterogeneity between studies and inconsistency results by removing studies identified as possibly causing heterogeneity and including inconsistent combinations, respectively.

Supplementary analyses were conducted to evaluate the heterogeneity between baseline characteristics among trials included.

All concentrations of the same medication were combined in the same group except for bimatoprost $0.01 \%$ and bimatoprost $0.03 \%$.

\section{RESULTS}

Of the 2642 publications identified by the systematic review and the 114 studies used by Li et al, 106 RCTs met the a priori eligibility criteria and were included (figure 1; references of these RCTs are listed in online supplemental appendix C). Of these, 11 (10\%) were published between 2014 and 2020. The total number of participants contributing to this network is 18523 (complete characteristics of included studies are listed in online supplemental appendix D.

Of the 106 trials, risk of selection bias (online supplemental appendix E) was rated as low for 54 (51\%) and 33 (31\%) studies when assessing sequence generation or allocation concealment, respectively, whereas the remaining trials were rated as having an 'unclear risk' except for one study with a 'high risk' in allocation concealment. Risk of performance bias, associated with blinding of participants, was rated as low (ie, reported blinding), high (ie, reported not blinding) or unclear (ie, not reported or unclear), for $42 \%, 37 \%$ and $21 \%$ of studies, respectively. Risk of detection bias, associated with blinding of the outcome assessor, was rated as low (ie, reported blinding), high (ie, reported not blinding) or unclear risk (ie, not reported) for 24\%, 63\% and 13\% of studies, respectively. Of the 69 articles who reported funding for their research, 64 (93\%) were funded by the industry. Of the 55 articles that reported financial relationship, 15 (27\%) declared having no financial conflict of interest.

The 106 studies included compared 16 interventions (figure 2). A total of 138 direct comparisons were performed based on 93 two-arm trials, 11 three-arm trials and 2 four-arm trials. Results of the pairwise meta-analysis are presented in table 1 . LBN was

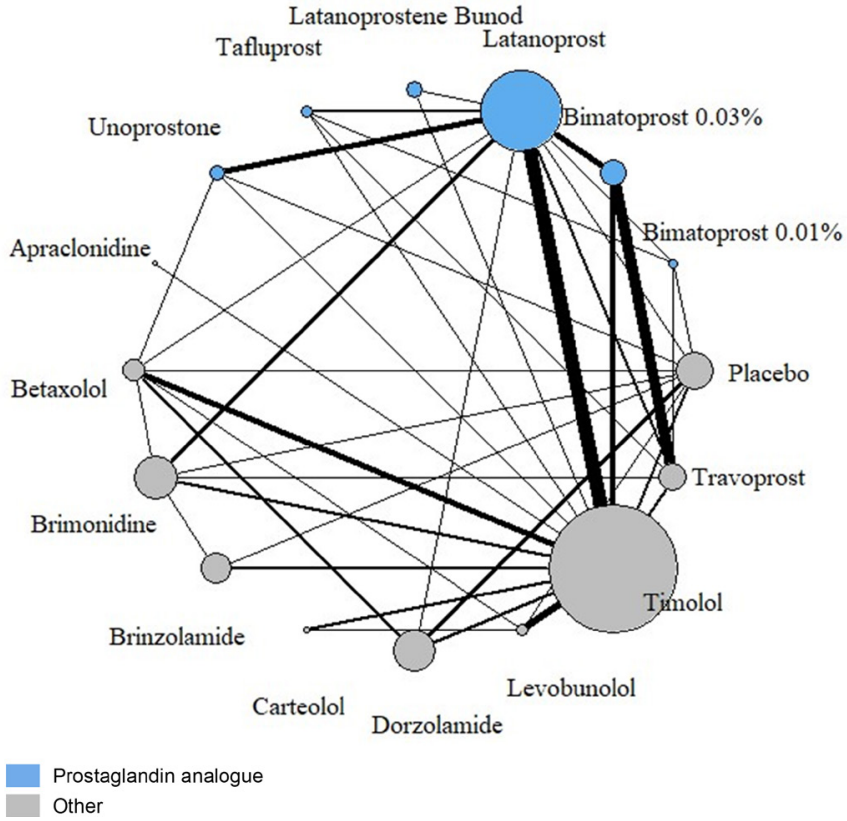

Figure 2 Network Graph. The nodes are weighted according to the number of participants randomised to that drug. The edges are weighted according to the number of direct comparison studies between drugs.

compared with timolol in two studies and latanoprost in one study. In both cases, LBN significantly lowers IOP more than the other treatments after 3 months (LBN vs timolol: MD (95\% $\mathrm{CI})=-1.42(-1.84$ to -1.01$)$ and $\mathrm{LBN}$ vs latanoprost: -1.23 $(-1.76$ to -0.70$))$.

Results of the NMA indicate that, when compared with placebo, all active drugs demonstrate an improved reduction of IOP at 3 months (table 2 and online supplemental appendix F). More specifically, the MDs in IOP reduction at 3 months for active drug in comparison to placebo range from $-1.97 \mathrm{~mm}$ $\mathrm{Hg}$ for unoprostone to $-5.59 \mathrm{~mm} \mathrm{Hg}$ for bimatoprost $0.03 \%$ and are all statistically significative. Importantly, LBN shows the second greatest reduction in IOP vs placebo with an MD (95\% CrI) of $-5.42 \mathrm{~mm} \mathrm{Hg}(-6.68$ to -4.16$)$. Furthermore, these results highlight the statistically significant superiority in efficacy of LBN compared with the PGA unoprostone $(-3.45$ $(-4.77$ to -2.12$))$ and the beta-blockers apraclonidine $(-2.55$ $(-4.52$ to -0.55$))$, betaxolol $(-2.89(-4.17$ to -1.60$)$ ), brimonidine $(-1.75(-3.02$ to -0.49$))$, brinzolamide $(-2.88$ $(--4.29$ to -1.47$))$, carteolol $(-2.17(-3.65$ to -0.69$)$ ), dorzolamide $(-2.87(-4.17$ to -1.55$))$ and timolol $(-1.69$ $(-2.80$ to -0.58$))$. Although the relative effect was not significative, compared with other PGAs, LBN numerically outperformed latanoprost $(-0.70(-1.83$ to 0.43$))$ and tafluoprost $(-0.41(-1.87$ to 1.07$))$, was similar to bimatoprost $0.01 \%$ $(-0.02(-1.59$ to 1.55$))$ and bimatoprost $0.03 \%$ demonstrated a slightly advantage over LBN ( -0.17 ( -1.42 to 1.07$)$ ) (table 2 and online supplemental appendix F). The model ranked each treatment by their relative effect (probabilities of being more effective) (table 3). According to these results, treatment with the higher probability of being ranked first is bimatoprost $0.03 \%$ with a probability of $37 \%$, followed by LBN with a probability of $29 \%$. LBN has a probability of $51 \%$ to be under the two best treatments and $70 \%$ to be under the three best treatments. Cumulative probability of being the most effective 
Table 1 Summary estimates for intraocular pressure at 3 months derived from the pairwise meta-analysis

\begin{tabular}{|c|c|c|c|c|c|c|c|}
\hline \multirow[b]{2}{*}{ Control } & \multirow[b]{2}{*}{ Experimental } & \multirow[b]{2}{*}{ Total no of studies } & \multirow{2}{*}{$\begin{array}{l}\text { Mean } \\
\text { difference* }\end{array}$} & \multicolumn{2}{|l|}{$95 \% \mathrm{Cl}$} & \multirow[b]{2}{*}{$\tau^{2} \dagger$} & \multirow[b]{2}{*}{$I^{2} \ddagger$} \\
\hline & & & & Low & Up & & \\
\hline \multirow[t]{9}{*}{ Placebo } & Bimatoprost $0.01 \%$ & 1 & -4.60 & -5.60 & -3.60 & NA & NA \\
\hline & Latanoprost & 1 & -3.10 & -3.98 & -2.22 & NA & NA \\
\hline & Unoprostone & 1 & -0.30 & -1.50 & 0.90 & NA & NA \\
\hline & Betaxolol & 2 & -3.16 & -4.17 & -2.15 & 0.3 & $52 \%$ \\
\hline & Brimonidine & 1 & -2.30 & -3.99 & -0.61 & NA & NA \\
\hline & Brinzolamide & 1 & -2.22 & -3.48 & -0.96 & NA & NA \\
\hline & Dorzolamide & 4 & -2.48 & -3.84 & -1.12 & 1.3 & $76 \%$ \\
\hline & Levobunolol & 2 & -7.90 & -8.94 & -6.85 & 0.0 & $0 \%$ \\
\hline & Timolol & 4 & -3.75 & -4.75 & -2.76 & 0.6 & $58 \%$ \\
\hline \multirow[t]{3}{*}{ Bimatoprost $0.01 \%$} & Latanoprost & 2 & 1.02 & 0.68 & 1.37 & 0.0 & $0 \%$ \\
\hline & Tafluprost & 1 & 2.30 & -0.91 & 5.51 & NA & NA \\
\hline & Travoprost & 2 & 1.50 & -1.98 & 4.97 & 5.2 & $80 \%$ \\
\hline \multirow[t]{2}{*}{ Bimatoprost $0.03 \%$} & Latanoprost & 7 & 0.99 & 0.46 & 1.53 & 0.3 & $61 \%$ \\
\hline & Travoprost & 8 & 0.44 & -0.52 & 1.40 & 1.4 & $86 \%$ \\
\hline \multirow[t]{4}{*}{ Latanoprost } & Latanoprostene bunod & 1 & -1.23 & -1.76 & -0.70 & NA & NA \\
\hline & Tafluprost & 3 & -0.99 & -1.92 & -0.07 & 0.0 & $0 \%$ \\
\hline & Unoprostone & 6 & 2.90 & 2.16 & 3.63 & 0.3 & $37 \%$ \\
\hline & Travoprost & 7 & -0.15 & -1.30 & 1.00 & 1.9 & $87 \%$ \\
\hline Apraclonidine & Timolol & 2 & -0.44 & -3.91 & 3.03 & 5.6 & $89 \%$ \\
\hline \multirow[t]{5}{*}{ Betaxolol } & Latanoprost & 2 & -1.84 & -3.22 & -0.47 & 0.0 & $0 \%$ \\
\hline & Unoprostone & 1 & 0.60 & 0.09 & 1.11 & NA & NA \\
\hline & Dorzolamide & 2 & -0.21 & -0.82 & 0.40 & 0.0 & $0 \%$ \\
\hline & Levobunolol & 2 & -4.65 & -10.13 & 0.84 & 13.3 & $84 \%$ \\
\hline & Timolol & 6 & -1.30 & -2.46 & -0.13 & 1.2 & $67 \%$ \\
\hline \multirow[t]{5}{*}{ Brimonidine } & Latanoprost & 5 & -1.22 & -2.13 & -0.31 & 0.8 & $78 \%$ \\
\hline & Betaxolol & 1 & 2.00 & 0.90 & 3.10 & NA & NA \\
\hline & Brinzolamide & 2 & 0.90 & 0.39 & 1.42 & 0.0 & $0 \%$ \\
\hline & Timolol & 4 & 0.42 & 0.04 & 0.81 & 0.0 & $0 \%$ \\
\hline & Travoprost & 1 & -1.20 & -3.77 & 1.37 & NA & NA \\
\hline Brinzolamide & Dorzolamide & 2 & -0.34 & -0.84 & 0.16 & 0.0 & $0 \%$ \\
\hline \multirow[t]{2}{*}{ Carteolol } & Levobunolol & 1 & -2.90 & -4.59 & -1.21 & NA & NA \\
\hline & Timolol & 4 & -0.27 & -1.11 & 0.57 & 0.4 & $60 \%$ \\
\hline Dorzolamide & Latanoprost & 1 & -2.90 & -3.70 & -2.10 & 0.0 & NA \\
\hline Levobunolol & Timolol & 9 & 0.11 & -0.40 & 0.62 & 0.1 & $15 \%$ \\
\hline \multirow[t]{8}{*}{ Timolol } & Bimatoprost $0.03 \%$ & 6 & -2.06 & -2.36 & -1.75 & 0.0 & $0 \%$ \\
\hline & Latanoprost & 15 & -1.18 & -1.65 & -0.70 & 0.6 & $76 \%$ \\
\hline & Latanoprostene bunod & 2 & -1.42 & -1.84 & -1.01 & 0.0 & $0 \%$ \\
\hline & Tafluprost & 2 & -0.50 & -1.12 & 0.12 & 0.1 & $38 \%$ \\
\hline & Unoprostone & 2 & 0.94 & -0.43 & 2.31 & 0.9 & $87 \%$ \\
\hline & Brinzolamide & 3 & 1.10 & 0.52 & 1.69 & 0.0 & $0 \%$ \\
\hline & Dorzolamide & 4 & 0.99 & 0.34 & 1.64 & 0.1 & $26 \%$ \\
\hline & Travoprost & 4 & -0.89 & -1.26 & -0.52 & 0.0 & $0 \%$ \\
\hline Travoprost & Tafluprost & 1 & -1.30 & -2.93 & 0.33 & NA & NA \\
\hline Total & 16 drugs & $138 \S$ & & & & & \\
\hline
\end{tabular}

, PGA

*Difference between the reduction in IOP during the study of the experimental drug and the control drug (mean difference under 0 favours the experimental drug). Results presented in bold are significant.

$\dagger \tau^{2}$ describes the underlying between-study variability.

$\mp l^{2}$ is the percentage of variability in the treatment estimates which is attributable to heterogeneity.

$\$ 106$ trials considered: 93 two-arm trials, 11 three-arm trials and 2 four-arm trials.

IOP, intraocular pressure; NA, not available; PGA, prostaglandin analogue.

treatment was calculated and the cumulative ranking curve of each treatment (presented in online supplemental appendix G) was obtained to calculate the SUCRA. According to SUCRA results, $\mathrm{LBN}(\mathrm{SUCRA}=88 \%)$ emerges as the second best treatment after bimatoprost $0.03 \%$ (94\%) and followed in order by bimatoprost $0.01 \%(87 \%)$, tafluprost $(78 \%)$, travoprost $(73 \%)$, levobunolol (72\%), latanoprost (68\%), timolol (48\%), brimonidine (47\%), carteolol (38\%), apraclonidine (30\%), dorzolamide (23\%), brinzolamide (22\%), betaxolol (22\%), unoprostone (11\%) and placebo (0\%). 


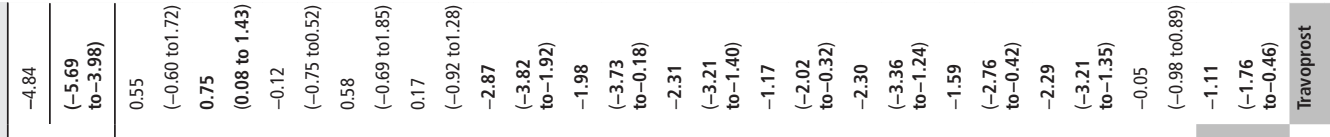

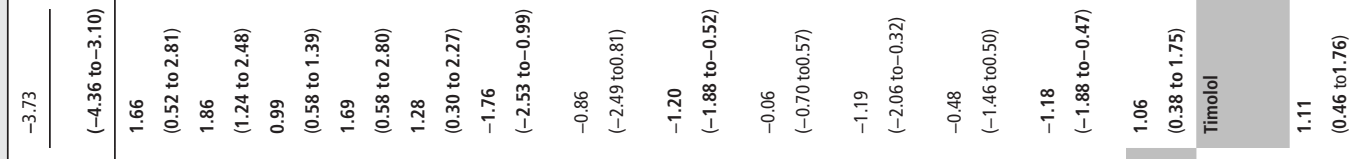

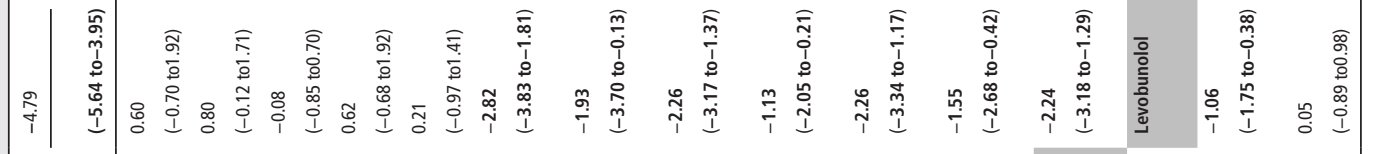

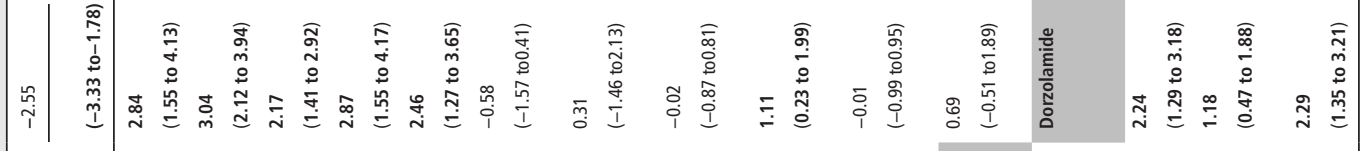

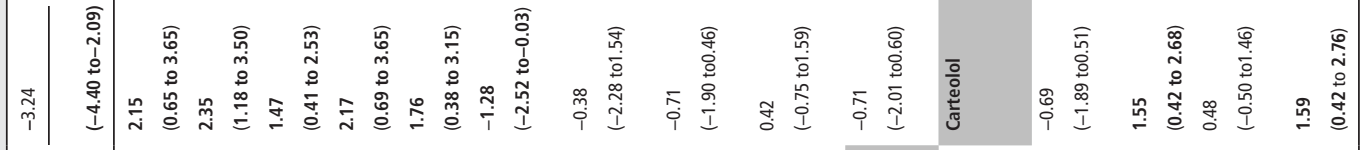
月)

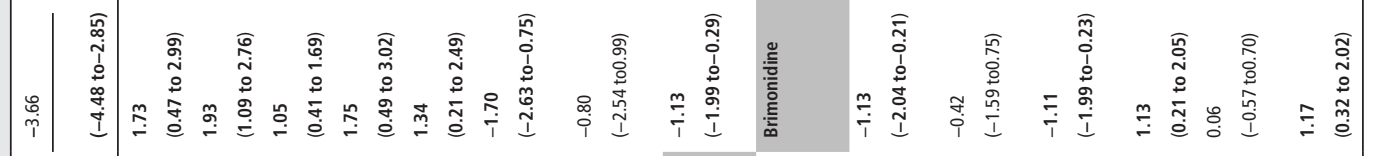

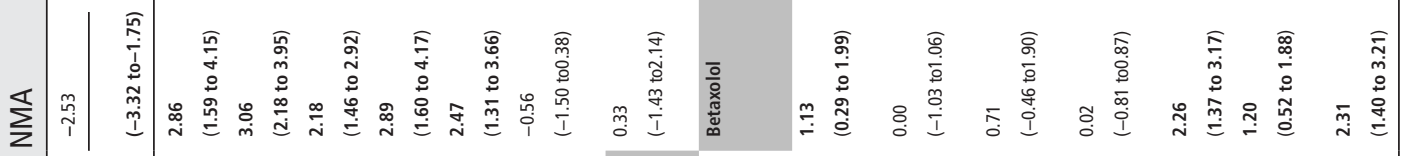

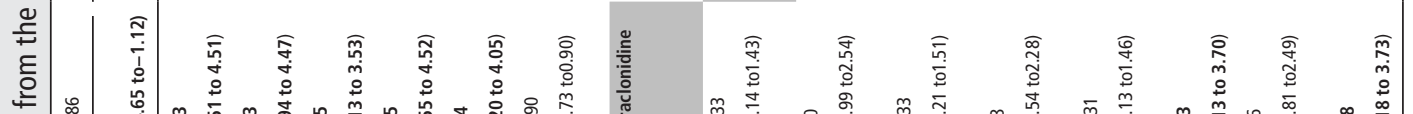

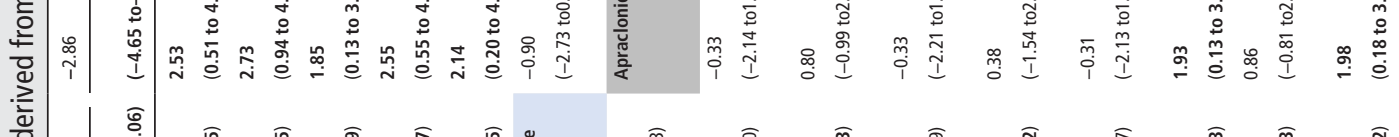

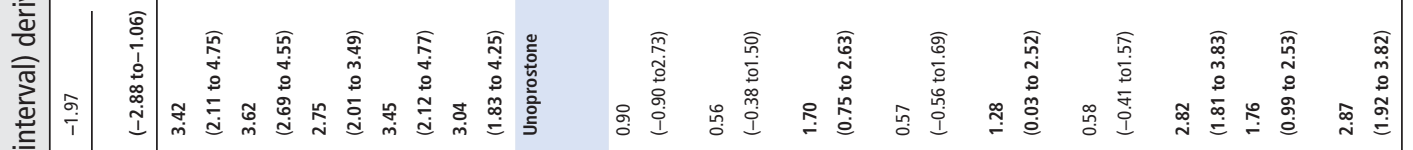

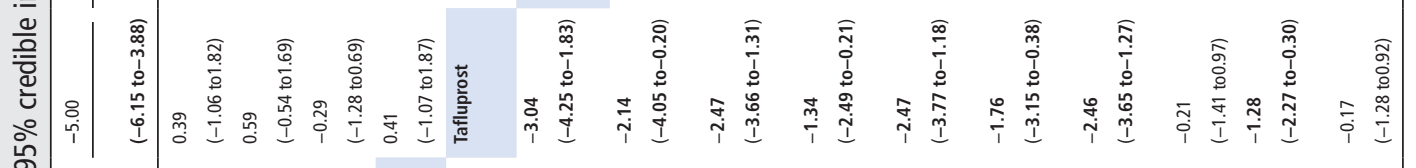

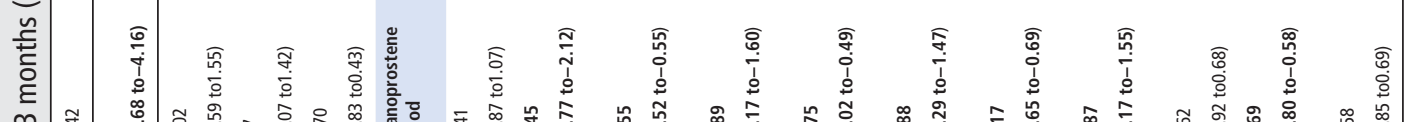

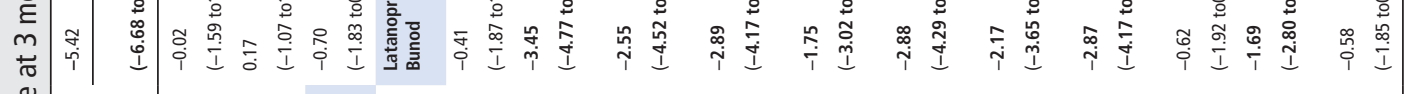

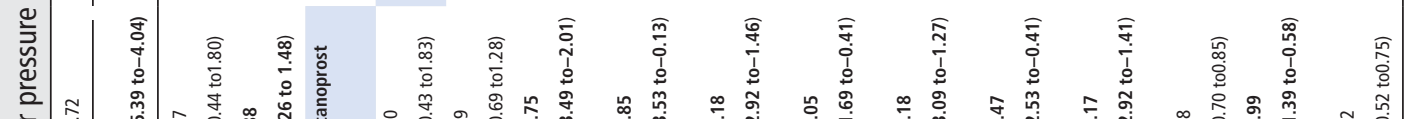

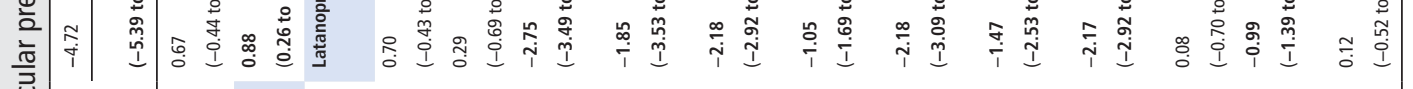

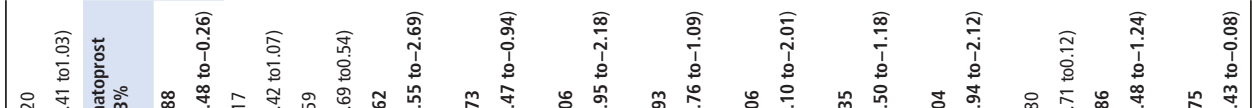

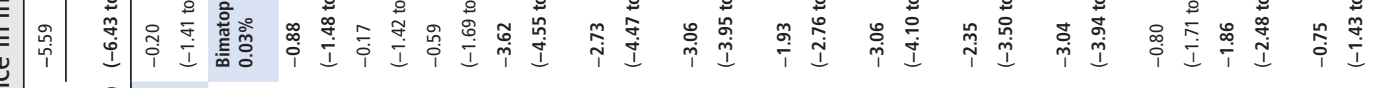

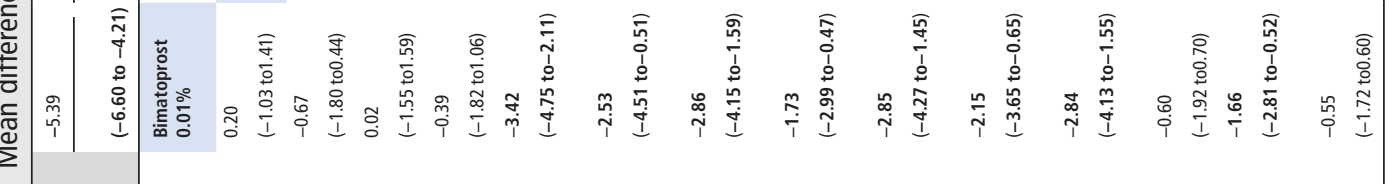

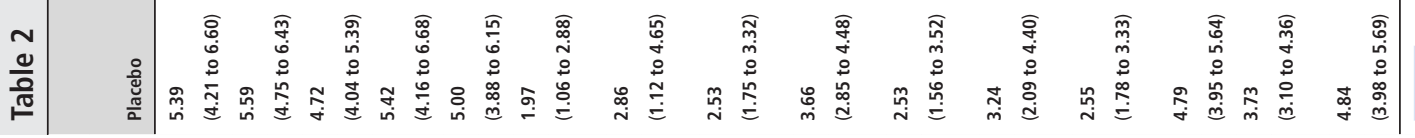




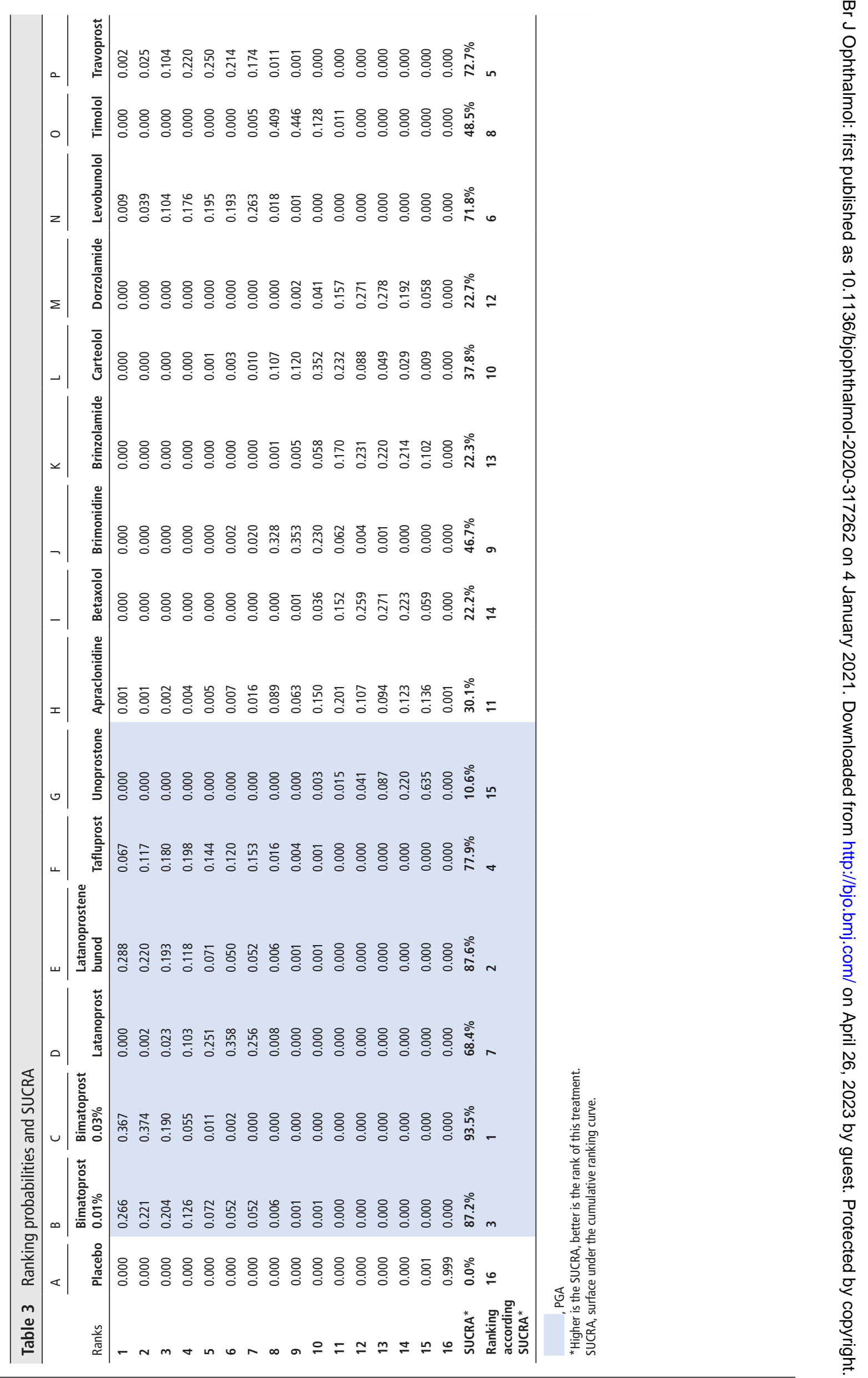




\section{Sensitivity analyses}

A total of 10 direct comparisons were identified as possibly causing heterogeneity (online supplemental appendix $\mathrm{H}$ ). When excluding these studies, the sensitivity analysis revealed no significant change in the NMA results (online supplemental appendix I). LBN was still significantly better than unoprostone and non-PGAs treatments, except for levobunolol and travoprost that was numerically superior. Although the relative effect was not significative, compared with other PGAs, LBN numerically outperformed latanoprost $(-0.72$ ( -1.60 to 0.16$))$, tafluoprost $(-0.60(-1.80$ to 0.61$))$ and bimatoprost $0.01 \%(-0.40(-1.70$ to 0.83$)$ ) and bimatoprost $0.03 \%$ demonstrated a slight advantage over LBN $(0.13$ ( -0.88 to 1.10$))$.

The node-splitting approach allowed for the identification of two inconsistent nodes (levobunolol vs placebo and timolol vs levobunolol) (online supplemental appendix J). When excluding these nodes, the sensitivity analysis revealed no significant change in the NMA results. Compared with unoprostone (PGA) and other non-PGAs, results indicated that LBN was significantly better, excluding travoprost but including levobunolol (online supplemental appendix I). Compared with other PGAs, although the relative effect was not significative, LBN was still numerically superior to latanoprost $(-0.66(-1.60$ to 0.31$))$, similar to bimatoprost $0.01 \%(0.09(-1.30$ to 1.50$))$ and disadvantaged by bimatoprost $0.03 \%(0.20(-0.87$ to 1.30$))$.

Four supplementary analyses were also conducted to evaluate the heterogeneity between baseline characteristics among trials by considering: (1) only studies published from 2000 onward, (2) studies with a washout period before randomisation, (3) studies that excluded prior glaucoma and cataract surgery, and (4) studies that excluded prior glaucoma laser. These analyses revealed that heterogeneity between baseline characteristics had no significant impact on the NMA results (online supplemental appendix K).

Also, the Brooks-Gelman-Rubin plot (online supplemental appendix L) illustrates that the NMA model converges.

\section{DISCUSSION}

The objective of this study was to assess the relative efficacy of a new IOP-lowering medication, LBN, compared with other topical medications for the treatment of POAG and $\mathrm{OH}$ and to provide a relative ranking of these treatments. Findings from this NMA confirm that all drugs are more effective when compared with the placebo. Importantly, results also indicate that LBN is significantly more effective than unoprostone (PGA) and other non-PGAs drugs except levobunolol and travoprost for which LBN is numerically better although not significant. This demonstrates that LBN is more effective than timolol, which aligns with the conclusion drawn from the individual studies (APOLLO and LUNAR). ${ }^{13}{ }^{14}$ Moreover, compared with other PGAs, LBN was numerically more effective than tafluoprost, similar to bimatoprost $0.01 \%$ and slightly disadvantaged by bimatoprost $0.03 \%$.

This systematic review was adapted from the one conducted by Li et al that was previously published in a peer-reviewed journal. ${ }^{11} \mathrm{~A}$ clear research question was formed using the PICO framework and the analysis was conducted based on the predefined protocol. It should be noted that of the 114 trials eligible in the NMA published by Li et al, 19 were not included in this NMA. This is explained by the fact that our systematic review was limited to English or French publications, whereas Li et al did not impose any language restriction. Moreover, some full-text articles were not accessible via the databases exploited for this study. Nonetheless, results presented herein are consistent with the findings of $\mathrm{Li}$ et al. Indeed, when comparing PGAs in terms of IOP reduction at 3 months, the intraclass differences are relatively small and not significantly meaningful. In addition, this systematic review and NMA, which include the most recent PGA, namely LBN, provides new findings relevant to clinicians and decisionmakers as it allows for the comparison of drugs that had not yet been evaluated in head-to-head trials.

It should be noted that there are some limitations associated with this NMA. First, although an NMA represents a powerful tool and may provide crucial information, an inherent limitation associated with NMA resides in the variability and the risk of biases of studies included. Due to possible variability between studies and between the comparisons made, a critical step when performing an NMA consists of validating the homogeneity and consistency assumptions. The sensitivity analyses conducted did not significantly alter the results, suggesting that the assumptions and conclusions made based on the statistical analysis are reliable and robust.

Second, this NMA focused on IOP reduction and did not include visual field outcomes. We acknowledge that the ultimate goal in the management of glaucoma consists of slowing or stopping structural damages leading to vision loss and that, consequently, visual field outcomes would be more clinically meaningful than IOP when comparing treatment response. However, due to the lag time between onset of optic neuropathy and clinically detectable visual field defects, the use of visual field outcomes to assess relative effectiveness of different interventions requires an extended time frame which poses challenges to the conduct of RCTs. Thus, although IOP does not measure structural of functional glaucomatous optic neuropathy, it remains the most commonly used surrogate endpoint of RCTs. ${ }^{102022} \mathrm{Li}$ et al reported that only $11 \%$ of trials included in their NMA reported any analysable visual field data. Moreover, the authors mentioned that since visual field data were reported in many different ways, the conduct of a pairwise meta-analysis or NMA would have been impossible. ${ }^{11}$ Finally, although our study provided a relative ranking of topical treatments for glaucoma based on IOP reduction at 3 months, the choice of treatment remains a multifactorial decision to take into consideration different factors, such as patient's medical history and preference, risk factors and likelihood of compliance.

\section{CONCLUSION}

Results from the NMA showed that, LBN was significantly more effective than the PGA unoprostone and most of the beta-blockers. Although there was no significant relative effect, compared with the most widely used PGAs, LBN was numerically more efficient than latanoprost and tafluoprost, was similar to bimatoprost $0.01 \%$ and was slightly disadvantaged by bimatoprost $0.03 \%$. LBN could potentially become a promising option for glaucoma patients.

Contributors $\mathrm{PH}$ analysed the data and drafted and revised the manuscript for important intellectual content. CR designed the study, acquired and analysed the data, drafted the initial manuscript and reviewed the manuscript. AXC, MB, KJ-G, $K M, J L$ and $C B$ designed the study and reviewed the manuscript.

Funding This research was funded by Bausch Health, Canada Inc.

Competing interests $\mathrm{PH}$ has received consultant honoraria from Bausch Health, Canada. CR is an employee of PeriPharm Inc. AXC, MB and KJ-G are employees of Bausch Health, Canada. KM is an employee of PeriPharm and Université de Montréal. JL and CB have received research funds from Bausch Health, Canada to conduct this study. 
Patient consent for publication Not required.

Provenance and peer review Not commissioned; externally peer reviewed.

Data availability statement Data are available on reasonable request.

Supplemental material This content has been supplied by the author(s). It has not been vetted by BMJ Publishing Group Limited (BMJ) and may not have been peer-reviewed. Any opinions or recommendations discussed are solely those of the author(s) and are not endorsed by BMJ. BMJ disclaims all liability and responsibility arising from any reliance placed on the content. Where the content includes any translated material, BMJ does not warrant the accuracy and reliability of the translations (including but not limited to local regulations, clinical guidelines, terminology, drug names and drug dosages), and is not responsible for any error and/or omissions arising from translation and adaptation or otherwise.

Open access This is an open access article distributed in accordance with the Creative Commons Attribution Non Commercial (CC BY-NC 4.0) license, which permits others to distribute, remix, adapt, build upon this work non-commercially, and license their derivative works on different terms, provided the original work is properly cited, appropriate credit is given, any changes made indicated, and the use is non-commercial. See: http://creativecommons.org/licenses/by-nc/4.0/.

\section{ORCID iD}

Jean Lachaine http://orcid.org/0000-0002-0791-2518

\section{REFERENCES}

1 Weinreb RN, Aung T, Medeiros FA. The pathophysiology and treatment of glaucoma: a review. JAMA 2014:311:1901-11.

2 Pascolini D, Mariotti SP. Global estimates of visual impairment: 2010. Br J Ophthalmol 2012:96:614-8.

3 Harasymowycz P, Birt C, Gooi P, et al. Medical management of glaucoma in the 21st century from a Canadian perspective. J Ophthalmol 2016;2016:1-22.

4 Tham Y-C, Li X, Wong TY, et al. Global prevalence of glaucoma and projections of glaucoma burden through 2040: a systematic review and meta-analysis. Ophthalmology 2014;121:2081-90.

5 Chang EE, Goldberg JL. Glaucoma 2.0: neuroprotection, neuroregeneration, neuroenhancement. Ophthalmology 2012;119:979-86.

6 Canadian Ophthalmological Society. Canadian Ophthalmological Society evidencebased clinical practice guidelines for the management of glaucoma in the adult eye, 2009

7 Maclver S, MacDonald D, Prokopich CL. Screening, diagnosis, and management of open angle glaucoma: an evidence-based guideline for Canadian optometrists. Can J Optometry 2017;79.
8 Jansen JP, Fleurence $R$, Devine $B$, et al. Interpreting indirect treatment comparisons and network meta-analysis for health-care decision making: report of the ISPOR Task force on indirect treatment comparisons good research practices: Part 1. Value Health 2011:14:417-28

9 Higher formulation of bimatoprost to be discontinued [press release] 2012.

10 Rouse B, Cipriani A, Shi Q, et al. Network meta-analysis for clinical practice guidelines: a case study on first-line medical therapies for primary open-angle glaucoma. Ann Intern Med 2016;164:674-82.

11 Li T, Lindsley K, Rouse B, et al. Comparative effectiveness of first-line medications for primary open-angle glaucoma: a systematic review and network meta-analysis. Ophthalmology 2016;123:129-40.

12 Nicox's Partner Secures Additional Approval of VYZULTA® (latanoprostene bunod ophthalmic solution), $0.024 \%$ in Taiwan [press release] 2020.

13 Medeiros FA, Martin KR, Peace J, et al. Comparison of Latanoprostene Bunod 0.024\% and Timolol Maleate $0.5 \%$ in Open-Angle Glaucoma or Ocular Hypertension: The LUNAR Study. Am J Ophthalmol 2016;168:250-9.

14 Weinreb RN, Liebmann JM, Martin KR, et al. Latanoprostene Bunod 0.024\% in Subjects With Open-angle Glaucoma or Ocular Hypertension: Pooled Phase 3 Study Findings. J Glaucoma 2018:27:7-15.

15 Weinreb RN, Ong T, Scassellati Sforzolini B, et al. A randomised, controlled comparison of latanoprostene bunod and latanoprost $0.005 \%$ in the treatment of ocular hypertension and open angle glaucoma: the VOYAGER study. Br J Ophthalmol 2015;99:738-45.

16 Hutton B, Salanti G, Caldwell DM, et al. The PRISMA extension statement for reporting of systematic reviews incorporating network meta-analyses of health care interventions: checklist and explanations. Ann Intern Med 2015;162:777-84.

17 The Cochrane collaboration. Assessing risk of bias in included studies. In: Cochrane Handbook for Systematic Reviews of Interventions, 2011. http://handbook-5-1. cochrane.org/

18 Higgins JPT, Thompson SG, Deeks JJ, et al. Measuring inconsistency in meta-analyses. BMJ 2003;327:557-60.

19 Gert van Valkenhoef JK. Package 'gemtc', 2016. Available: https://cran.r-project.org/ web/packages/gemtc/gemtc.pdf [Accessed 1 Aug 2018].

20 Salanti G, Ades AE, loannidis JPA. Graphical methods and numerical summaries for presenting results from multiple-treatment meta-analysis: an overview and tutorial. J Clin Epidemiol 2011;64:163-71.

21 Mbuagbaw L, Rochwerg B, Jaeschke R, et al. Approaches to interpreting and choosing the best treatments in network meta-analyses. Syst Rev 2017;6:79.

22 Medeiros FA. Biomarkers and surrogate endpoints in glaucoma clinical trials. $\mathrm{Br}$ Ophthalmol 2015;99:599-603. 